\title{
Probing the surface chemistry of different oxidized MWCNT for the improved electrical wiring of cytochrome c nitrite reductase
}

Célia M. Silveira ${ }^{\mathrm{a}}$, Marta Pimpão ${ }^{\mathrm{a}}$, Humberto A. Pedroso ${ }^{\mathrm{a}}$, Patrícia R.S. Rodrigues ${ }^{\mathrm{a}}$, José J.G. Moura $^{\mathrm{a}}$, Manuel F.R. Pereira ${ }^{\mathrm{b}}$, M. Gabriela Almeida ${ }^{\mathrm{a}, \mathrm{c}^{*}}$

a REQUIMTE - Dep. Química, CQFB, Faculdade de Ciências e Tecnologia, Universidade Nova de Lisboa, 2829-516 Caparica, Portugal

${ }^{b}$ LCM - Laboratório de Catálise e Materiais, Laboratório Associado LSRE/LCM, Dep. Engenharia Química, Faculdade de Engenharia, Universidade do Porto, 4200-465 Porto, Portugal

${ }^{c}$ Instituto Superior de Saúde Egas Moniz, 2829-511 Caparica, Portugal

* CORRESPONDING AUTHOR:

e-mail: mg.almeida@fct.unl.pt

Telephone:+351 212948300 


\begin{abstract}
This work reports the evaluation of a set of multi-walled carbon nanotubes (MWCNT) presenting different surface chemistries, as interfaces for the direct electrochemistry of the multihemic nitrite reductase (ccNiR) from Desulfovibrio desulfuricans ATCC27774 $(D d)$. The carbon nanotubes dispersions were prepared in aqueous media and deposited on pyrolytic graphite (PG) macroelectrodes, following a layer-by-layer methodology. The resulting MWCNT bed was coated with $\mathrm{c} c \mathrm{NiR}$ and studied by cyclic voltammetry. Interestingly, although small non-catalytic cathodic waves were detected in all carbon nanotubes bioconjugates, the complexity of these electrochemical signals was partially deconvoluted in some materials, the less acidic ones emphasizing the contribution of the catalytic centre. Consistently, these MWCNT were the most favourable for enzyme catalysis, highlighting the importance of the surface oxide functionalities to enzyme reactivity.
\end{abstract}

Keywords: multi-walled carbon nanotubes, surface oxides, nitrite reductase, direct electrochemistry 


\section{Introduction}

Carbon nanotubes (CNT) are among the most studied nanostructured materials in the field of (bio)electrochemistry. CNT electrodes are usually characterized by improved electrocatalytic activity, which can be mostly attributed to the large surface active areas and facilitated heterogeneous electron transfer (ET) with these interfaces [1-7]. However, CNT are insoluble in almost all solvents which makes their manipulation rather difficult, greatly restricting their use in (bio)electrochemistry $[6,8]$. To overcome this issue, the introduction of structural defects and oxide functional groups through chemical oxidation with strong acids has been successfully used [5,9].

A good example of CNT usefulness in bioelectrochemistry is shown by the ammonia forming enzyme, $c c \mathrm{NiR}$, which delivered much higher catalytic currents and sensitivities with plain single-walled carbon nanotubes modified electrodes [10]. In its simplest structure, $c c \mathrm{NiR}$ is composed of two different subunits, so called NrfA and $\mathrm{NrfH}$, in a $\alpha_{2} \beta$ configuration. NrfA houses five hemes including the catalytic site, whereas $\mathrm{NrfH}$ contains four, making a total of 14 hemes per trimer [11].

In this study, we tested a variety of chemically and thermally modified MWCNT in order to further promote $c c \mathrm{NiR}$ 's catalytic activity. The MWCNT samples were previously prepared and characterized by Gonçalves et al. [12]. Briefly, the original MWCNT sample (MWCNT_orig) was chemically oxidized with $\mathrm{HNO}_{3}$ (MWCNT$\mathrm{HNO}_{3}$ ) introducing oxygenated groups which were selectively removed by subsequent gas-phase thermal treatments at 400 and $600^{\circ} \mathrm{C}$ (MWCNT_HNO ${ }_{3} 400$ and 600). In parallel, sample MWCNT_orig was also subjected to gas-phase oxidation with $\mathrm{O}_{2}$ at $500^{\circ} \mathrm{C}$ (MWCNT_O ${ }_{2} \_500$ ). The resulting materials had different surface chemistries and textural properties, as described in detail in ref. [12] ( $c f$. Table 1).

All MWCNT samples were water suspended and deposited at PG electrodes, serving in this way as electrode interfaces for ccNiR. The enzyme's voltammetric response in each material was related with its surface properties. 


\section{Experimental section}

\subsection{Reagents}

ccNiR (1.0 mg/mL; $300 \mathrm{U} / \mathrm{mg}$ ) was purified from $D d$ as previously described [11]. Sodium nitrite, tris(hydroxymethyl)aminomethane and potassium chloride were from Merck and tetrahydrofurane (THF) from Fisher. Solutions were prepared with deionized water (18 M $\Omega . c m)$ from a Millipore MilliQ purification system. All chemicals were analytical grade.

Five MWCNT samples were previously treated as described in ref. [12]. The original material: MWCNT_orig was purchased from Nanocyl 3100.

\subsection{MWCNT dispersions}

The MWCNT were dispersed in deionized water $(0.1 \mathrm{mg} / \mathrm{mL})$ by sonication during 30 minutes. Because the non-treated material, MWCNT_orig lacked hydrophilic functional groups, it had to be sonicated in the organic solvent THF.

\subsection{Bioelectrode preparation}

The electrodes were modified by consecutively casting $10 \mu \mathrm{L}$ of MWCNT dispersions and drying the solvent of each layer at $65^{\circ} \mathrm{C}$. After five layers had been deposited, electrodes were rinsed with solvent. A $10 \mu \mathrm{L}$ drop of enzyme was then applied onto the electrodes and dried at room temperature.

\subsection{Electrochemical measurements}

Electrochemical measurements were performed with a Potentiostat Autolab PGSTAT12 (Eco-Chemie) monitored by GPES 4.9 software (Eco-Chemie). A three-electrode cell composed of a reference saturated calomel electrode (SCE; Radiometer), a platinum counter electrode (Radiometer) and a self-made PG (basal plane, $\Phi<4 \mathrm{~mm}$ ) as working electrode. Experiments were performed at room temperature $\left(20 \pm 2^{\circ} \mathrm{C}\right)$ under an argon atmosphere. 
Cyclic voltammograms (CVs) were plotted using a scan rate of $20 \mathrm{mVs}^{-1}$ in the potential window [-0.1;-0.8] V (supporting electrolyte, $0.1 \mathrm{M} \mathrm{KCl}, 0.050 \mathrm{M}$ tris- $\mathrm{HCl}$, $\mathrm{pH}$ 7.6). To evaluate the bioelectrode's response to nitrite, $\mathrm{NaNO}_{2}$ standard solutions were added to the cell. After each addition, the cell was argon purged and the CV was recorded. Catalytic currents were determined at the inversion potential $(-0.8 \mathrm{~V})$. All potentials were quoted against SCE.

The analysis of non-catalytic CVs of ccNiR was performed with SOAS software [13].

\section{Results and Discussion}

\subsection{Characterization of MWCNT/cc NiR bioelectrodes}

The water dispersed samples of the chemically and thermally modified MWCNT were tested as enhancers of the electroactivity of $c c \mathrm{NiR}$ at PG electrodes, either in the presence or absence of the enzyme's substrate. Although not directly comparable, results were evaluated in parallel with those obtained with MWCNT_orig (THF dispersed), and with bare PG surfaces.

\subsubsection{Non-catalytic response}

The CVs of $c c$ NiR immobilized in electrodes modified with five layers of each type of MWCNT are represented in Fig. 1. As expected from the electrode surface enlargement, all CVs had high capacitive currents $[1,14]$. Although, these currents vary between the bioelectrodes, which could suggest different amounts of deposited materials, the electroactive areas [determined with the redox probe $\mathrm{Fe}(\mathrm{CN})_{6}$ ] were quite similar between the different MWCNT materials (ca. $0.12 \mathrm{~cm}^{2}$ ); compared to bare PG electrodes $\left(0.10 \mathrm{~cm}^{2}\right)$, this represents an increase of only $17 \%$. At this point, it is not possible to judge whether this is a matter of a low amount of carbon nanotubes or material conductivity properties.

Non-catalytic signals of $c c$ NiR were obtained with every MWCNT material. No signals were observed in control electrodes prepared without c $c$ NiR (not shown). In general, a rather broad unresolved wave with low intensity was observed in the cathodic potential scan (ca. - $0.4 \mathrm{~V}$ vs SCE) which may enclose the reduction of all the heme cofactors through internal ET, as previously proposed in ref. [15]. Yet, no significant anodic 
peaks were observed. Remarkably, a careful examination of each cathodic wave using the SOAS software (allows the elimination of background and capacitive currents and, therefore, the observation of Faradaic currents alone [13]) indicated some differences between cathodic signals in terms of peak positions and half-widths (insets of Fig. 1). The widths at half height, for example, were ca. 150, 50, 170, 310 and $280 \mathrm{mV}$ for MWCNT_orig, MWCNT_O 2 500, MWCNT_HNO $3, \quad \mathrm{MWCNT} \_\mathrm{HNO}_{3} \_400$ and MWCNT_HNO $3 \_600$ bioelectrodes, respectively. In almost all cases, the broad wave appears to be comprised of highly overlapping peaks, and with some materials, more than one peak could be distinguished (Fig. 1C-E). Most likely, the number of heme groups being monitored is varying. The most noticeable difference comes from the MWCNT_O 2 _500 material, for which a considerably less broad reduction signal was observed (Fig. 1B). The peak position also shifted about $+50 \mathrm{mV}$, being closer to the reduction potential of the catalytic heme $(\approx-340 \mathrm{mV}$ vs SCE). Apparently, the MWCNT_O ${ }_{2} 500$ interface rich in carbonyls, quinones/phenols and with a few anhydrides [12] displays preferential direct ET with the active site of $\mathrm{c} c \mathrm{NiR}$ (heme 1). At this point, one might question why the width is not as broad as in the signals obtained with the other MWCNT. Possibly, the specific protein orientation obstructs direct electron delivering from the electrode interface to the remaining heme groups and there is no internal ET between hemes (the two closest cofactors to heme 1 have reduction potentials much more negative: -642 and $-722 \mathrm{mV}$ vs SCE), thereby hindering electron tunnelling [11]. This is a remarkable result, since the deposition method employed here does not allow any control regarding protein orientation.

Clearly, the chemical nature of the MWCNT surface determined $c c$ NiR's interaction with the electrode interface and enabled the deconvolution of the electrochemical response. Such effect was not seen before in previous direct ET studies of $c c \mathrm{NiR}$.

Because of its potential, the first peak (i.e. the less negative one) detected in these complex electrochemical signals can possibly be assigned to the catalytic centre of $\mathrm{c} c \mathrm{NiR}$. In order to isolate this peak, a further analysis of each $\mathrm{CV}$ was made with SOAS (Fig. 1F). Once again, the resulting signals highlight the specific features displayed on MWCNT_O 2 _500 films: the cathodic peak is narrower and has a less negative potential when compared to all other materials.

Unfortunately, no heterogeneous ET rate constants were measured, because the electrochemical signals of $\mathrm{c} c \mathrm{NiR}$ were not reversible and were completely lost at sweep rates higher than $20 \mathrm{mVs}^{-1}$. 


\subsubsection{Electrocatalytic response to nitrite}

The PG electrodes modified with the different samples of MWCNT and $c c N i R$ were also tested by $\mathrm{CV}$ in the presence of nitrite. The current-potential profiles were identical with all materials as exemplified in Fig. 2A for the $c c$ NiR/5-MWCNT_O ${ }_{2} 500$ electrodes.

The bioelectrodes exhibited a catalytic peak at $c a$. $-0.4 \mathrm{~V}$ vs SCE, reflecting the electroenzymatic reduction of nitrite to ammonium. The current increased as a function of nitrite concentration in a typical Michaelis-Menten saturation curve (Fig. 2B). The catalytic response was characterized in terms of the linear range, sensitivity, maximum current and catalytic efficiency - $\mathrm{J}_{\max } / \mathrm{J}_{\text {initial }}$ - defined as "maximum current density (at saturating nitrite concentration, $1 \mathrm{mM}$ )/initial current density" (Table 1).

When compared to the non-modified CNT and bare PG surfaces all treated materials provided a better response (Table 1). The best results were obtained with the MWCNT_O ${ }_{2} 500$ and $\mathrm{MWCNT}{ }_{-} \mathrm{HNO}_{3}{ }_{6} 600$ bioconjugates. Actually, the MWCNT_O ${ }_{2}$ 500 based bioelectrodes had already displayed a distinctive behaviour in the absence of nitrite. This material provided the highest sensitivities and catalytic efficiencies. Conversely, the $c c \mathrm{NiR} / \mathrm{MWCNT} \_\mathrm{HNO}_{3} 600$ bioelectrodes delivered the top one maximum (catalytic) current density, suggesting that the heme cofactors should be responding to the electrode in a faster manner and/or in higher number.

In order to understand the effect of the surface properties of the treated MWCNT on the performance of the bioelectrodes, the maximum current densities were plotted against their surface/textural properties (Fig. 2C-D). The nanotubes surface areas $\left(\mathrm{S}_{\mathrm{BET}}\right.$; Brunauer-Emmett-Teller, $c f$. Table 1) were not considered since the differences are very small and did not influence the electroactive area of the MWCNT modified electrodes, as mentioned above. Interestingly, a lower mass percentage of surface oxygen $\left(\% \mathrm{~m}_{\mathrm{O}}\right)$ delivers higher $\mathrm{J}_{\max }$ values (Fig. 2C). Though, it is generally accepted that the presence of oxygenated groups provides more compatible sites for enzyme interaction [3]. In its turn, the evaluation of the influence of the MWCNT' acid-base character (point of zero charge, $\mathrm{pH}_{\mathrm{PZC}}$ ) indicates that the less charged surfaces were more convenient for enzyme turnover (Fig. 2D). Because these parameters $\left(\% \mathrm{~m}_{\mathrm{O}}, \mathrm{pH}_{\mathrm{PZC}}\right)$ are indissociable, at this point, we cannot discriminate which one prevails. However, it is probably the electrostatic nature of the chemical functionalities and not their total amount that 
governs the interactions with $\mathrm{c} c \mathrm{NiR}$. As so, it is somewhat surprising that the MWCNT with less negatively charged sites are the most adequate for the enzyme's electrocatalytic activity, contrasting the general notion that carboxyl rich surfaces (such as the edge-plane like defects in CNT), are the best ones to facilitate charge transfer processes [16]. Perhaps the presence of electron-withdrawing groups slowed down the heterogeneous ET kinetics [17]. Moreover, the existence of the NrfH hydrophobic subunit of ccNiR [11] may explain the preference for less oxygenated surfaces.

\section{Conclusions}

In this work, a number of selected MWCNT with different surface chemistries were tested as promoters of the direct electrochemical response of $c c \mathrm{NiR}$. The use of nanostructured electrodes with a low content of acidic groups provided a very sensitive method for the electrochemical determination of nitrite. More importantly, some of these MWCNT partially resolved the complex non-catalytic voltammetric response of $\mathrm{c} c \mathrm{NiR}$, which has never happened before. Most likely, the surface features of these materials can modulate protein orientation on the electrode surface.

In conclusion, the different surface oxide coverages proved to be valuable interfaces to probe the intrinsic properties of this redox protein and perhaps to selectively study the catalytic heme.

\section{Acknowledgments}

The authors thank the financial support from Fundação para a Ciência e Tecnologia (SFRH/BPD/79566/2011) and REQUIMTE (PEst-C/EQB/LA0006/2011).

\section{References}

[1] J.J. Davis, K.S. Coleman, B.R. Azamian, C.B. Bagshaw, M.L. Green, Chemistry, 9 (2003) 3732-3739.

[2] C. Gao, Z. Guo, J.-H. Liu, X.-J. Huang, Nanoscale, 4 (2012) 1948-1963.

[3] J.J. Gooding, Electrochim Acta, 50 (2005) 3049-3060.

[4] C.B. Jacobs, M.J. Peairs, B.J. Venton, Anal Chim Acta, 662 (2010) 105-127. 
[5] R.L. McCreery, Chem Rev, 108 (2008) 2646-2687.

[6] G.A. Rivas, M.D. Rubianes, M.C. Rodriguez, N.F. Ferreyra, G.L. Luque, M.L. Pedano, S.A. Miscoria, C. Parrado, Talanta, 74 (2007) 291-307.

[7] J. Wang, Electroanalysis 17 (2005) 7-14.

[8] D. Vairavapandian, P. Vichchulada, M.D. Lay, Anal Chim Acta, 626 (2008) 119129.

[9] K. Balasubramanian, M. Burghard, Small, 1 (2005) 180-192.

[10] C.M. Silveira, J. Baur, M. Holzinger, J.J.G. Moura, S. Cosnier, M.G. Almeida, Electroanalysis, 22 (2010) 2973-2978.

[11] M.G. Almeida, S. Macieira, L.L. Goncalves, R. Huber, C.A. Cunha, M.J. Romao, C. Costa, J. Lampreia, J.J. Moura, I. Moura, Eur J Biochem, 270 (2003) 3904-3915.

[12] A.G. Gonçalves, J.L. Figueiredo, J.J.M. Órfão, M.F.R. Pereira, Carbon, 48 (2010) 4369-4381.

[13] V. Fourmond, K. Hoke, H.A. Heering, C. Baffert, F. Leroux, P. Bertrand, C. Léger, Bioelectrochemistry, 76 (2009) 141-147.

[14] L. Zhao, H. Liu, N. Hu, Anal Bioanal Chem, 384 (2006) 414-422.

[15] M.G. Almeida, C.M. Silveira, B. Guigliarelli, P. Bertrand, J.J. Moura, I. Moura, C. Leger, FEBS Lett, 581 (2007) 284-288.

[16] A. Chou, T. Bocking, N.K. Singh, J.J. Gooding, Chem Commun, (2005) 842-844.

[17] L.R. Radovic, I.F. Silva, J.I. Ume, J.A. Menéndez, C.A.L.Y. Leon, A.W. Scaroni, Carbon, 35 (1997) 1339-1348. 


\section{Figure and Table Captions}

Fig. 1. CVs of the non-catalytic response of $c c N i R / 5-M W C N T$ electrodes: A) MWCNT_orig (THF suspension), B) MWCNT_O $2 \_500$, C) MWCNT_HNO 3 , D) MWCNT_HNO ${ }_{3} 4400$, E) MWCNT_HNO ${ }_{3}$ 600; Insets: Baseline subtraction on cathodic scan. F) Isolation of the less negative peak of each cathodic scan. Scan rate, 20 $\mathrm{mVs}^{-1}$. Electrolyte, 0.1 M KCl, $50 \mathrm{mM}$ tris- $\mathrm{HCl}, \mathrm{pH}$ 7.6.

Fig. 2. Electrocatalytic response of $c c \mathrm{NiR} / 5-\mathrm{MWCNT}$ electrodes to nitrite. $c c \mathrm{NiR} / 5$ MWCNT_O 2 500 A) CVs with varying nitrite concentrations: a-d) 0, 10, 20 and 50 $\mu \mathrm{M}$. Scan rate, $20 \mathrm{mVs}^{-1}$; electrolyte, $0.1 \mathrm{M} \mathrm{KCl}$ in tris- $\mathrm{HCl}$ buffer $50 \mathrm{mM} \mathrm{pH} \mathrm{7.6;} \mathrm{B)}$

Michaelis-Menten plot of catalytic currents $v s$ nitrite concentration. $\mathrm{K}_{\mathrm{M}}{ }^{\text {app }} 1.17 \pm 0.07$ $\mathrm{mM}, \mathrm{I}_{\max }{ }^{\text {app }}-163 \pm 4 \mu \mathrm{A}$. Effect of the surface properties of the MWCNT on maximum current density: C) Brunauer-Emmett-Teller surface area; D) mass percentage of surface oxygen; E) point of zero charge. Values are the average of three independent determinations.

Table 1. Effect of the type of modified MWCNT on the bioelectrode response to nitrite in $0.1 \mathrm{M} \mathrm{KCl}, 50 \mathrm{mM}$ tris- $\mathrm{HCl}, \mathrm{pH} 7.6$. Values are the average of three independent determinations. ${ }^{a}$ Nanotubes dispersed in THF. MWCNT modification and characterization data was taken from ref. [12], $\mathrm{S}_{\mathrm{BET}}-$ Brunauer-Emmett-Teller surface area, $\% \mathrm{~m}_{\mathrm{O}}-$ mass percentage of oxygen on the surface, $\mathrm{pH}_{\mathrm{PZC}}-$ point of zero charge. 